\title{
Formação de professores a distância e as perspectivas de articulação entre teoria e prática por meio de ambientes on-line
}

\section{Distance teacher training and perspectives of theory and practice integration through online environments}

\author{
Maria Elizabeth Bianconcini de Almeida ${ }^{1}$ \\ Katia Alexandra de Godoi e Silva ${ }^{1}$
}

\begin{abstract}
RESUMO
O objetivo deste artigo reside na articulação da teoria e prática nas intervenções, a partir do pressuposto de que esta articulação é uma categoria fundante na formação inicial e continuada, facilitada pelos ambientes on-line. Desta forma, no início do texto, trata-se da formação inicial de professores e da articulação entre teoria e prática nas modalidades presencial e a distância; para, em seguida, abordar a formação continuada de professores, numa perspectiva de articulação por meio de ambientes on-line. No tópico seguinte, aborda-se um design metodológico e design-based research, que orienta um estudo sobre a articulação teoria e prática em um contexto específico de formação continuada em um ambiente on-line. E, ao final, os resultados da análise partem das reflexões dos professores sobre a escolha e avaliação de materiais didáticos digitais no contexto da própria prática.

Palavras-chave: formação de professores a distância; articulação entre teoria e prática; ambiente on-line.
\end{abstract}

\section{ABSTRACT}

The aim of this paper lies in the theory and practice integration on interventions, from the assumption that this combination is a foundational

DOI: $10.1590 / 0104-4060.38657$

1 Pontifícia Universidade Católica de São Paulo, Programa de Pós-Graduação em Educação: Currículo, Faculdade de Educação. São Paulo, São Paulo, Brasil. Rua Ministro Godoi, 969, Prédio novo, Andar 4, Sala 4E15. CEP: 05015-901. 
category on initial and continuing training, facilitated by online environments. Thus, at the beginning of the text, we deal with teachers' initial training and the theory and practice integration in the face-to-face and distance modes. We then approach teachers' continuing training under the perspective of integration through online environments. In the next topic we deal with a methodological design and design-based research, which guides a study on the theory and practice integration in a specific context of continuing training in an online environment. And in the end, the analysis' results bring teachers' reflections on the choice and evaluation of digital learning materials in the context of their own practice.

Keywords: distance teacher training; theory and practice integration; online environment.

\section{Introdução}

No Brasil, a formação de professores não é preocupação recente. De modo geral, tem sido sempre discutida por alguns autores (NÓVOA, 1995; PACHECO, 1995; GIMENO SACRISTÁN; PÉREZ GOMES, 1998; GARCÍA, 1999; TARDIF; LESSARD, 2005; IMBERNÓN, 2009, 2010).

Nossa intenção, neste artigo, não é analisar os momentos históricos pelos quais passou e/ou tem passado a formação de professores, nem tampouco suas perspectivas. Nosso propósito é apenas tecer algumas considerações sobre as formações inicial e continuada por meio de ambientes on-line.

Este trabalho trata especificamente da articulação entre teoria e prática como eixo da formação a partir do pressuposto de que essa articulação é uma categoria fundante, nem sempre concretizada, nas formações inicial e continuada de professores e que pode ser impulsionada pelo uso de ambientes on-line. Com base na literatura, é apresentado, a princípio, o panorama da formação inicial nas modalidades presencial e a distância, relatando estudos que mostram a disjunção entre teoria e prática, e outros que enfatizam a integração.

Em seguida, adentra-se na formação continuada de professores, com ênfase nas perspectivas de articulação entre teoria e prática propiciada pela midiatização de ambientes on-line e analisa-se um contexto específico de formação, que se concretizava na reflexão sobre a ação dos professores participantes do projeto intitulado "O Currículo da Escola do Século XXI - Integração das TIC ao Currículo: Inovação, Conhecimento Científico e Aprendizagem”, financiado pelo edital do "Programa um Computador por Aluno" (PROUCA 2010) do Conselho Nacional de Desenvolvimento Científico e Tecnológico (CNPq), Coordenação 
de Aperfeiçoamento de Pessoal de Nível Superior (Capes) e Ministério da Educação (MEC).

Este estudo está delimitado à formação de educadores de uma escola participante do PROUCA, localizada no Município de Campo Limpo Paulista, estado de São Paulo, por meio do ambiente on-line e-Proinfo. Nessa escola, a formação era de responsabilidade direta da Pontifícia Universidade Católica de São Paulo (PUC-SP).

\section{A formação inicial de professores e articulação da teoria e prática nas modalidades presencial e a distância}

A Lei de Diretrizes e Bases da Educação Nacional (9.394, de 20 de dezembro de 1996) trouxe dois desafios para a formação de professores no Brasil, ao estabelecer, em seu artigo 62, a exigência de formação em nível superior para o exercício da docência na educação básica e ao propor, no artigo 80 , a oferta de programas a distância, em todos os níveis e modalidades de ensino (BRASIL, 1996).

Para atender à legislação nacional e garantir mudanças nos números da educação do País, são canalizados recursos para formar enorme contingente de professores em exercício na educação básica, sem a devida titulação em nível superior, que impulsionam a expansão dos cursos de Licenciatura presenciais. Logo após a regulamentação da Educação a Distância $(\mathrm{EaD})$, há também aumento desses cursos nessa modalidade. A dimensão que essa política atinge se expressa em resultados numéricos do Censo do Ensino Superior (INEP, 2013), conforme mostra o Quadro 1, em relação às matrículas na graduação no ano de 2011.

QUADRO 1 - DISTRIBUIÇÃO DO NÚMERO DE MATRÍCULAS DE GRADUAÇÃO POR MODALIDADE DE ENSINO, SEGUNDO O GRAU ACADÊMICO - BRASIL - 2011

\begin{tabular}{|l|c|c|c|c|}
\hline \multicolumn{2}{c}{ Presencial } & \multicolumn{2}{c|}{ A distância } \\
\hline Grau acadêmico & Matrículas & Percentual & Matrículas & Percentual \\
\hline Bacharelado & 4.196 .423 & 73,0 & 299.408 & 30,20 \\
\hline Licenciatura & 926.780 & 16,1 & 429.549 & 43,30 \\
\hline Tecnológico & 606.564 & 10,6 & 263.970 & 26,60 \\
\hline Não se aplica & 16.996 & 0,3 & --- & 0 \\
\hline
\end{tabular}

FONTE: Censo da Educação Superior (INEP, 2013, p. 57). 
De acordo com o Quadro 1, a distribuição das matrículas nos cursos de graduação classificados conforme o grau acadêmico (Bacharelado, Tecnológico, Licenciatura, Não se aplica), segundo a modalidade de ensino (presencial ou a distância), mostra que os cursos de Licenciatura na modalidade presencial atingem $16,1 \%$, entre aqueles da mesma modalidade, enquanto os cursos de Licenciatura a distância correspondem a 43,3\% do total de matrículas no ensino superior a distância.

O elevado percentual de matrículas dos cursos de Licenciatura a distância indica a relevância de se desenvolverem estudos sobre essa modalidade de formação de professores, considerando-se o que recomendam as Diretrizes Curriculares Nacionais para os Cursos de Licenciatura, instituídas pela Resolução CNE/CP 01/2006, no parágrafo $2^{\circ}$ do artigo $2^{\circ}$, em relação ao seu desenvolvimento, que ocorre "por meio de estudos teórico-práticos, investigação e reflexão crítica” (BRASIL, 2006).

Em que pese essa recomendação, Gatti e Nunes (2009) analisam os currículos dos cursos presenciais de Licenciatura em Pedagogia, Língua Portuguesa, Matemática e Ciências Biológicas, e apontam distorções no cumprimento das concepções, dos princípios e fundamentos preconizados, com a predominância de abordagens de caráter mais descritivo-teórico, em detrimento das abordagens que relacionam a teoria com a prática, além da ausência de conteúdos das disciplinas ensinadas na educação básica. Em relação ao curso de Pedagogia, Saviani (2011) denuncia a separação entre a teoria e a prática, a legislação e a realidade.

Gatti e Barreto (2009) constatam o aumento na oferta de cursos de Licenciatura; identificam nova configuração na formação de professores na modalidade a distância e reconhecem a existência de um embate na visão de estudiosos sobre a $\mathrm{EaD}$, principalmente no que se refere à formação de professores, com dois polos antagônicos. Em um dos polos, situam-se os defensores da EaD segundo a ótica da democratização do acesso ao ensino superior e da melhoria da qualidade da educação básica; no outro polo, colocam-se aqueles que responsabilizam a EaD por sucatear o ensino, torná-lo desumano e aderente às políticas de globalização.

Giolo (2008) aborda a EaD no Brasil sob os ângulos da legislação, do panorama da educação superior e da história e performance atual, bem como aponta problemas que a EaD cria para a formação docente, devido ao fato de não se realizar em sala de aula presencial, espaço inerente do ensinar, do aprender, e das relações humanas que norteiam a prática docente. Na mesma linha, Barreto (2008, p. 932) acentua que "a recontextualização das TIC na política nacional de formação de professores a distância tem sido produzida pela negação das condições históricas da formação e do trabalho docente". 
De fato, a EaD é uma modalidade educativa, em que os processos de ensino e aprendizagem são midiatizados pelas tecnologias em uso, as quais estruturam os modos de interagir e representar o conhecimento. Mas, são as intenções, necessidades e os interesses do homem que direcionam os usos das tecnologias, que representam uma dimensão da cultura (VIEIRA PINTO, 2005). Isso indica que a formação inicial de professores na modalidade a distância pode potencializar problemas situados na formação de professores de modo mais amplo, os quais precisam ser enfrentados desde sua concepção e estrutura.

Almeida, Iannone e Silva (2012) realizaram estudo documental e de campo sobre o curso de Pedagogia a distância em oito instituições de ensino superior (IES), públicas e privadas, situadas em distintas regiões do Brasil, e identificaram três IES em que as práticas não se limitavam às atividades dos estágios curriculares e quatro IES que consideravam o estágio como elemento inerente do exercício da prática. Isso sugere que metade das IES investigadas não valorizava a atividade de estágio para a construção da prática dos futuros professores, prática que se constrói por meio do compartilhamento de experiências, da reflexão e da articulação com a teoria.

Outra posição mostra-se, sobretudo, quando as análises incidem sobre cursos específicos, com foco na proposta pedagógica, nos princípios, componentes, na metodologia, nos papéis de professores, tutores e alunos. Aragón, Menezes e Novak (2013) analisam o Curso de Graduação em Pedagogia - Licenciatura na Modalidade a Distância (PEAD), desenvolvido pela Universidade Federal do Rio Grande do Sul, em consórcio com a Universidade Federal de Santa Catarina (UFSC).

O curso tem arquitetura pedagógica aberta, organização interdisciplinar estruturada em eixos e interdisciplinas, que articulam metodologias interativas e o uso das Tecnologias Digitais de Informação e Comunicação (TDIC). O currículo desenvolve-se a partir da experiência dos alunos, que são professores em exercício nas redes municipais de ensino, com aprofundamento em teorias que qualifiquem as práticas pedagógicas. Para tal, as atividades propostas no curso privilegiam a "presença" e a interação, com vistas a "encurtar distâncias" e superar o "isolamento".

Pires e Manrique (2007) analisam a proposta do curso de Licenciatura em Matemática da PUC-SP, oferecido nas modalidades presencial e a distância, cujos princípios orientadores pautam-se por estudos e reflexões sobre a prática, desenvolvidos em articulação com as atividades curriculares, com ênfase na resolução de situações problema, na análise e discussão de situações concretas da realidade escolar ou apresentadas por meio de recursos das TDIC, narrativas de professores, produções dos alunos e estudo de casos. 
Assim, a literatura disponível evidencia estudos que se apresentam em polos distintos. Da mesma maneira como ocorre na formação de professores na modalidade presencial, é possível identificar, nos cursos de Licenciatura a distância, a prevalência de currículos que continuam a dicotomizar teoria e prática, mesmo quando grande parte dos alunos exerce a docência na educação básica e teriam melhores oportunidades de refletir sobre a prática autêntica que realizam em sala de aula e de buscar teorias para melhor compreendê-la e transformá-la. Isso sugere que o problema da disjunção entre teoria e prática não reside na modalidade do curso e sim na concepção de formação, que se encontra impregnada, nos cursos de Licenciatura, e descortinam a crise neles existente, cujo enfrentamento demanda mudanças profundas na estrutura curricular, nas dinâmicas da formação e no funcionamento das instituições (GATTI, 2013).

Enfrentar essa problemática exige políticas claras, ações coerentes e articuladas. Uma das iniciativas para tal é representada pelo Programa Institucional de Bolsas de Iniciação à Docência (PIBID), criado por meio do Decreto 7.219, de 24 de junho de 2010. Executado no âmbito da CAPES, o PIBID tem a finalidade de promover a iniciação e formação qualificada de docentes em nível superior e a melhoria de qualidade da educação básica. Por meio desse Programa, o aluno de Licenciatura é inserido nas práticas escolares com a orientação de um professor da IES em que ele faz o seu curso e acompanhado pelo professor da escola (supervisor).

Abreu e Lanzarini (2013) analisam a implementação do PIBID na Universidade de Santa Cruz do Sul, estruturado em rede de aprendizagem constituída entre universidade (licenciandos e professores) e escolas públicas (professores), com suporte em um ambiente on-line, por meio do qual os participantes interagem, registram suas experiências e realizam atividades colaborativas que articulam teoria e prática, educação a distância e presencial.

Outra estratégia que pode ser adotada é a de ressignificar para o contexto da formação inicial as ações de formação continuada e em serviço, que se desenvolvem por meio da articulação entre teoria e prática, abordagem adotada em alguns projetos desenvolvidos em parceria com as redes públicas de ensino, que integram contextos de formação presencial e a distância com as práticas de sala de aula.

\section{Formação continuada de professores: perspectivas de articulação da teoria e prática por meio de ambientes on-line}

Os projetos desenvolvidos em parceria com as redes públicas de ensino, que integram contextos de formação continuada de professores na modalidade 
presencial e/ou a distância com as práticas de sala de aula, referem-se a uma formação que ocorre quando os professores estão em pleno exercício de sua profissão, após terem realizado a formação inicial (GARCÍA, 1999). Esses projetos de formação têm sido desenvolvidos e acompanhados pela linha de pesquisa de Novas Tecnologias em Educação, do Programa de Pós-Graduação em Educação: Currículo, da PUC-SP.

$\mathrm{O}$ projeto de que trataremos neste artigo refere-se a um recorte da pesquisa denominada "O Currículo da Escola do Século XXI - Integração das TIC ao Currículo: Inovação, Conhecimento Científico e Aprendizagem", financiada pelo edital PROUCA 2010, do CNPq, da CAPES e do MEC, e desenvolvida no período de setembro de 2011 a setembro de 2013, em uma escola no Município de Campo Limpo Paulista.

É importante ressaltar que a denominação "formação continuada de professores na modalidade on-line para o uso integrado das TDIC no contexto escolar" é utilizada, a partir de uma proposta, pautada nos princípios de interação entre os participantes, investigação, autoria, trabalho colaborativo e construção do conhecimento. Apoiada em referências teóricas e metodologias baseadas em princípios construcionistas, contextualizados, dialógicos e reflexivos, conforme evidenciado por Almeida (2012), Valente, Prado e Almeida (2005), Jonassen (1996), Duffy e Cunningham (1996), a formação tem como foco a experiência do aluno-professor, no intuito de agregar sua prática pedagógica ao processo de formação, articulando teoria e prática.

Por essa razão, a formação não pode apenas enfatizar os aspectos técnicos e/ou privilegiar os pressupostos teóricos das TDIC na educação. É preciso propiciar uma formação reflexiva e desencadeadora do processo de reconstrução da prática pedagógica dos alunos-professores (PRADO, 2003; VALENTE; PRADO; ALMEIDA, 2005; ALMEIDA, 2005; PRADO; ALMEIDA, 2007). Portanto, sob tal perspectiva, o processo de formação deve ser contextualizado (ALMEIDA, 2000, 2004), ou seja, deve levar em consideração os aspectos que emergem e se desenvolvem no local em que o aluno-professor atua e a análise de sua própria prática pedagógica à luz de teorias educacionais chamadas para dialogar com as práticas.

Entende-se que a teoria por si não tem força para promover transformações, assim como a prática não é suficiente para modificar a realidade. Teoria e prática são unidades distintas, que se inter-relacionam na práxis, sendo a práxis uma ação reflexiva, criadora e transformadora da teoria, da prática e do ser humano (SANCHEZ VAZQUEZ, 2007).

A partir desse panorama, busca-se apoio na abordagem pedagógica do "estar junto virtual" (VALENTE, 2000), que enfatiza a aprendizagem por meio das interações estabelecidas em um curso de formação de professores na mo- 
dalidade on-line, que aproxima professores-formadores e alunos-professores, e cria condições para atividades reflexivas, que favorecem a reconstrução do conhecimento.

No entanto, Prado e Almeida (2009) advertem que a recontextualização da abordagem do estar junto virtual, em um curso de formação de professores na modalidade on-line oferecido a alunos-professores que atuam em distintos contextos, exige flexibilidade do design educacional, considerando o design emergente, concebido, conforme destaca Cavallo (2003), como um ato de criação dinâmico. Por um lado, é necessário organizar, planejar e produzir previamente o curso e, por outro, não engessar e/ou padronizar a atuação e mediação pedagógica dos diferentes professores-formadores do curso, para atender às necessidades que emergem na prática.

Diante dessa necessidade de flexibilizar o design, Prado e Almeida esclarecem sobre a importância da mediação pedagógica do professor-formador com foco no acompanhamento e orientação das práticas do professor com seus alunos:

O professor no ambiente virtual pauta suas ações no acompanhamento investigativo do processo de aprendizagem dos alunos e na sua intencionalidade pedagógica para fazer as intervenções necessárias, recriando novas estratégias didáticas, desafiando cognitivamente e apoiando emocionalmente os alunos na busca de superações e de novos patamares de aprendizagem (PRADO; ALMEIDA, 2009, p. 67).

Embora a organização e a produção do curso sejam concebidas e implementadas previamente no ambiente on-line, os professores-formadores podem viabilizar, por meio da mediação pedagógica, a formação reflexiva e a contextualizada, permitindo ao professor-formador conhecer e participar das ações pedagógicas imediatas do aluno-professor no contexto escolar.

Tudo isso é possível por meio das interações e dos registros mediante os recursos disponíveis nos ambientes on-line, que propiciam, segundo Prado (2003): (1) o registro das ações dos alunos-professores - o que pretendem realizar e o que realmente acontece durante a ação na sala de aula; (2) o acompanhamento da ação do aluno-professor pelo professor-formador - a intervenção na prática pedagógica do aluno-professor no momento da sua ação. Assim, a mediação pedagógica do professor-formador favorece, ao aluno-professor, o aprendizado significativo do uso das TDIC no contexto de sua prática pedagógica, pois viabiliza a articulação entre teoria e prática, levando-o a refletir na e sobre sua ação (SCHÖN, 1995, 2000), assim como sobre a reflexão-na-ação (PRADO, 2003). 
Para Almeida (2006), a mediação pedagógica do professor-formador incide sobre a Zona Proximal de Desenvolvimento (ZPD) do aluno-professor e do grupo em formação, o que implica identificar os níveis real e potencial de desenvolvimento dos alunos-professores, formando uma espiral ascendente de aprendizagem (VALENTE, 2005), que acontece quando a espiral descrição-execução-reflexão-depuração-nova descrição é colocada em ação.

Nesse momento, é possível inferir que estão embutidos os três níveis de reflexão, nos quais o uso das TDIC traz importante contribuição à formação: a tomada de consciência do professor sobre seus avanços, suas dificuldades e possibilidades de mudanças na prática pedagógica (ALMEIDA, 2009), propiciando, assim, o conhecimento prático sistematizado, a reconstrução da prática e a ressignificação da teoria.

Portanto, articular teoria e prática na perspectiva transformadora (SANCHEZ VAZQUEZ, 2007), em um curso de formação em ambiente on-line, e proporcionar aos professores-formadores a aproximação da realidade do aluno-professor e de seu contexto, promovendo a reflexão, interação, autoria, colaboração, investigação e aprendizagem significativa do aluno-professor, requer a recontextualização da abordagem do estar junto virtual, a partir das características de cada contexto, assim como a compreensão e ressignificação do professor-formador sobre o design educacional do curso (VALENTE; PRADO; ALMEIDA, 2003; ALMEIDA; PRADO, 2007; PRADO; ALMEIDA, 2009).

Especificamente para a formação citada, o design educacional do curso envolveu intervenções presenciais, por meio de oficinas teórico-práticas e atividades a distância no ambiente on-line e-Proinfo, as quais tiveram como tema a reflexão sobre a escolha e avaliação de material didático digital ${ }^{2}$.

Para Godoi $(2009,2013)$, a avaliação do material didático digital constitui-se um dos múltiplos temas das TDIC na educação e conta com pesquisa extensa, de mais de 20 anos, com propostas de diversos autores.

Embora essa temática seja assunto da formação continuada dessa escola, tanto nas intervenções presenciais quanto a distância, no ambiente on-line, o foco deste artigo tem como eixo norteador a análise da articulação entre teoria e prática no ambiente on-line.

2 Consideramos como material didático digital: um recurso digital cujos elementos permitam a inserção de novas informações, expressão do pensamento, o estabelecimento de relações, desenvolvimento da interação social, compartilhamento de produções, trabalho em colaboração, a modelação, simulação, animação, a combinação multimídia, induzindo a estratégias de ensino e modos de aprendizagem diversificados e que podem ser orientados para a observação ou reprodução dos fenômenos, ou ainda para a aprendizagem de conceitos e teorias por meio da combinação de imagens, palavras e sons. 
Assim, para entender as características de cada contexto de formação e considerá-las no desenvolvimento da formação, é que foi definido o percurso metodológico da presente investigação.

\section{Percurso metodológico}

Considerando a diversidade sociocultural da investigação realizada em distintas realidades escolares, mas, ao mesmo tempo, retomando o recorte deste artigo, Almeida reitera a necessidade de uma metodologia de investigação que adote

tanto a abordagem teórica e documental, como a pesquisa de campo, realizada na prática concreta com ênfase na identificação das inter-relações evidenciadas no andamento do trabalho, alinhando-se com o paradigma qualitativo, com foco mais no processo do que nos resultados (ALMEIDA, 2013, p. 9).

Desse modo, a metodologia desta investigação aproxima-se do design metodológico e design-based research (design experiments), isto é, de metodologias desenhadas no decurso da pesquisa (REDIG, 2006; DBRC, 2003). De modo semelhante à metodologia da investigação coordenada por Almeida (2013), o design metodológico desta pesquisa se constitui em três etapas: diagnóstico, intervenção e análise, representadas na Figura 1.

Nesse esquema visual, é possível compreender, em resumo, o processo de design-based research, a partir da proposta de Reeves (2000): a investigação parte do diagnóstico de um problema educativo analisado em parceria com os sujeitos envolvidos na pesquisa e leva em conta as especificidades e necessidades do contexto; a intervenção ocorre em contexto presencial e/ou on-line e é considerada uma forma de desenvolver e analisar se os artefatos pedagógicos (ações da formação contextualizada) contribuíram para a solução do problema educativo e, a partir da análise da intervenção, princípios de design são desenvolvidos, no intuito de contribuir com o trabalho de outros pesquisadores e contextos.

A proposta deste artigo é analisar as intervenções da formação continuada no contexto on-line, que teve como eixo norteador a articulação entre teoria e prática, a partir das reflexões sobre a escolha e avaliação de materiais didáticos digitais. 


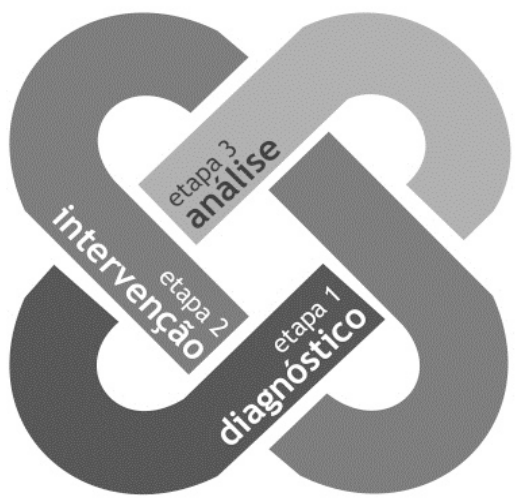

FIGURA 1 - ESQUEMA REPRESENTATIVO DAS ETAPAS DA PESQUISA

FONTE: Almeida (2003)

Assim, na formação, os alunos-professores eram convidados a registrar suas práticas e refletir sobre esses aspectos no ambiente on-line. Esses registros eram apresentados aos professores-formadores, cuja reflexão propiciava a busca de teorias para melhor compreendê-las e reconstruí-las. A teoria iluminava a compreensão, reelaboração e recontextualização da prática pedagógica, assim como a prática refletida conduzia à reconstrução da teoria.

Essas reflexões entre alunos-professores e professores-formadores propiciaram a convivência com os desafios, problemas e outros fatores que interferiam nas intervenções da formação no ambiente on-line, na busca conjunta de alternativas para sobrepujar as dificuldades, no compartilhamento de conquistas e fracassos (ALMEIDA, 2000, 2004), quando os professores-formadores e alunos-professores tinham a possibilidade de compreender o que, como, por que e para que (IMBERNÓN, 1998) usar e escolher os materiais didáticos digitais.

Nesse sentido, a seguir, explica-se a análise da articulação entre teoria e prática, que ocorre nessas intervenções, por meio dos registros dos alunos-professores no ambiente on-line e-Proinfo.

\section{Análise da articulação entre teoria e prática e reflexão sobre a ação}

A partir do design metodológico, que assumiu um caráter aberto e flexível pela possibilidade de proposições de intervenções, a análise desenvolvida para 
o recorte deste artigo focaliza e articula teoria e prática, a partir da reflexão dos alunos-professores sobre a escolha e a avaliação de materiais didáticos digitais, que ocorre antes, durante e após as ações de intervenção em contexto on-line na formação continuada.

Para Godoi (2013), essas reflexões enriquecem a análise centrada nas características do material didático digital, se for utilizada numa perspectiva de envolvimento dos alunos-professores e professores-formadores no processo de familiarização com os materiais; na reflexão sobre a exploração das potencialidades pedagógicas, à luz de concepções educacionais; na integração à prática pedagógica e ao currículo; e na criação de condições para favorecer a aprendizagem.

Nessa perspectiva, professores-formadores e alunos-professores constituem um grupo em formação. Todos têm a oportunidade de aprender, em situações problemáticas contextualizadas, as quais são analisadas pelo grupo em um processo contínuo de investigação, interação, cooperação e socialização, caracterizando um enfoque de formação contextualizada. Estabelece-se, assim, uma práxis contextualizada cujas reflexões indicam mudanças gestadas nas práticas pedagógicas dos alunos-professores e a ressignificação das teorias (ALMEIDA, 2000, 2004).

A partir dessas mudanças e com base em Schön $(1995,2000)$, a análise deste artigo é construída em três níveis que se complementam.

$\mathrm{O}$ primeiro nível refere-se à reflexão-na-ação com o uso das TDIC. Segundo Schön $(1995,2000)$, Almeida $(2000,2004)$ e Prado e Almeida (2009), o objetivo é reorganizar e desencadear, no aluno-professor, a necessidade de aprender a lidar com as situações surgidas durante a sua prática pedagógica, criando novas estratégias de ação.

Assim, a reflexão-na-ação refere-se aos pensamentos que ocorrem durante a prática (presente) pedagógica do professor, servindo para reorganizar essa prática no decurso de sua intervenção; esse processo favorece a criação de um conhecimento prático. $\mathrm{O}$ extrato a seguir releva os pensamentos de um professor durante sua prática.

No momento, escolhi trabalhar com a ferramenta [blog], criando com os alunos esse recurso para que se apropriem desta ferramenta e com isso contribuir para o letramento digital, favorecendo as habilidades de leitura e escrita. Procurei desenvolver também a capacidade de raciocínio e de comunicação, bem como o espírito crítico e a criatividade. Utilizamos a ferramenta do laptop webCam para fotografar as dependências da escola para postar no blog, com as atividades que estão sendo desenvolvidas com 
o uso do net, de acordo com o conteúdo abordado. Por ex.: a utilização do vídeo para gravar uma aula trabalhada com sinopse de filmes, no qual o ambiente foi preparado para este momento, discutimos sobre cada escolha do filme e sua sinopse; alguns alunos relataram o que entenderam deste tema, enquanto isso, estava sendo gravado. Outro trabalho foi a realização de uma receita em sala de aula do Bolo de Iogurte, que os alunos gravaram para postar no blog e depois puderam se deliciar com esse bolo. As atividades estão sendo desenvolvidas e, ao final, vão montar slides no KPresent, para apresentação de todo esse percurso aos pais e alunos da escola. Acredito estar sendo um trabalho relevante, já que os alunos estão gostando muito. [Professor Polivalente]

De modo geral, esse extrato confirma que o professor reflete sobre a ação, ou seja, durante sua prática (presente), considera diversos aspectos, como, por exemplo, letramento digital, competências e habilidades, características dos alunos, mobilidade, integração de mídias, avaliação, entre outras questões.

No entanto, para que ocorra a reflexão sobre a ação, que se refere ao segundo nível, Schön $(1995,2000)$ explica que o professor precisa pensar, retrospectivamente, sobre sua prática pedagógica, em um ambiente de tranquilidade, para que a reconstrua mentalmente, a partir da análise e descrição dos fatos ocorridos, compreendendo como lidou com a própria prática, bem como percebendo quais práticas educativas devem ser alteradas, como indica o extrato a seguir.

Por estar lecionando num 5ano, em que o conteúdo trabalhado envolve bastante a questão da análise de dados em gráficos e tabelas, desenvolvi aulas nas quais foi feita a transcrição de dados estudados, em gráficos e tabelas, no caderno e na apostila, para o netbook. Numa aula, entramos no ambiente escritório e utilizamos a ferramenta editor de planilha eletrônica (que permite efetuar cálculos, analisar informações e gerenciar listas em planilhas e transferir para gráficos). O uso dessa ferramenta permitiu a análise mais especifica dos dados e também foi uma forma mais efetiva de estudo e aprendizagem, pois os alunos manipulavam os dados e as informações em diferentes perspectivas e diferentes gráficos. Na elaboração do plano, o recurso escolhido foi a Internet e os materiais foram o processador de texto e a utilização da ferramenta para usar gráficos e tabelas na coleta de dados no decorrer das atividades. Esse plano tem como objetivo desenvolver nos alunos a consciência ambiental, promovendo a interação com o meio, atrelando os devidos conhecimentos adquiridos aos recursos tecnológicos, promovendo, portanto, o uso das 
ferramentas disponíveis no laptop, e os alunos utilizam seus próprios conhecimentos prévios das ferramentas e os desenvolvem com a intervenção e o objetivo da professora. Devido ao conhecimento já adquirido em relação à sala, foi apresentado, aos alunos, o plano a ser desenvolvido, com suas etapas já definidas, e, a partir dai, foi dado o ponto de partida para o desenvolvimento do plano. A sala de aula não tem uma única organização definida para a realização das atividades, uma vez que cada uma requer sua organização específica, ressaltando que algumas atividades serão realizadas fora da classe (extraclasse). Buscando, quando necessário, acoplar ao currículo. A cada etapa desenvolvida, reavalia-se o plano, a fim de verificar se o objetivo estabelecido está sendo alcançado, visando, assim, uma melhoria nas etapas seguintes, buscando melhor aprendizado do aluno, para que se torne algo significativo no processo de ensino-aprendizagem. Avaliando, em cada etapa, o desenvolvimento e a participação dos alunos, percebe-se que estão cada vez mais envolvidos com a junção das atividades realizadas manualmente com as tecnologias, querendo, sempre que possivel, fazer essa interligação. Porém, usamos menos do que gostaríamos, pois não conseguimos o tempo viável para tais atividades, uma vez que o conteúdo curricular do $5^{\circ}$ ano é um pouco extenso para o tempo disponível. [Professor de Matemática]

Esse extrato indica a reconstrução da prática pedagógica do professor, a partir da análise de seus objetivos, de seu planejamento, dos materiais didáticos digitais, da organização da sala de aula, da verificação e avaliação de sua prática, além do que ele gostaria de alterar para realizar novas ações.

Desta forma, na medida em que esse processo reflexivo evolui, ocorre a reflexão sobre a reflexão-na-ação, o que possibilita ao professor novos patamares de compreensão sobre a ação, "propiciando a sistematização do conhecimento prático e a reconstrução da prática pedagógica” (PRADO, 2003, p. 44).

Primeiro, quero deixar registrado aqui que o ser humano é o mais belo recurso tecnológico que existe e vive em eterna atualização de suas configurações; digo isso por minhas transformações internas; em minhas primeiras participações no fórum afirmei que escolhia os materiais didáticos digitais que mais se adequassem às minhas necessidades enquanto professora. Agora, após as formações, percebo quanto estava enganada e sendo egoísta. Não tenho que procurar algo para atender às minhas necessidades; tenho que escolher um material que desperte o interesse do aluno de forma que ele encontre subsidios para suprir suas necessidades enquanto educando. Ao escolher algo a ser trabalhado em sala de aula, 
temos que nos fazer um questionamento: Será que isso será significativo ao aluno? Será que vai contribuir para a formação de um sujeito autor de seu conhecimento? Enfim... como disse antes, estou revendo meus conceitos... [Professora de Informática]

Observa-se, no depoimento do aluno-professor, que primeiro ele reflete sobre a sua prática, a partir do conhecimento de suas necessidades docentes, e a intervenção do professor-formador incide sobre essa colocação, no sentido de provocar a ampliação do seu olhar para envolver o aluno, entendendo suas necessidades, seus saberes e significados.

O extrato confirma os novos patamares de compreensão estabelecidos pelo aluno-professor sobre a escolha de materiais didáticos digitais, ou seja, a partir das intervenções da formação, o aluno-professor sistematizou seu conhecimento prático e fez propostas que indicam a reconstrução de sua prática pedagógica e a reformulação de suas teorias. A partir da análise das especificidades das reflexões e da natureza das intervenções desenvolvidas ao longo da formação continuada, a teoria era trabalhada no sentido de subsidiar a reflexão sobre a prática e a transformação de ambas, conforme especifica o aluno-professor ao se referir às formações. A articulação entre teoria e prática foi evidenciada pelo fato de as intervenções terem enfatizado o aprendizado prático numa abordagem reflexiva e de forma articulada com a teoria.

Por fim, é importante salientar que os fundamentos pedagógicos desenvolvidos simultaneamente com as atividades de uso das TDIC, por meio da abordagem reflexiva, serviram como base para contextualizar a interpretação da teoria abordada, ao mesmo tempo em que a teoria também elucida e instiga olhares sobre a compreensão da prática, resultando na transformação de ambas, do próprio aluno-professor e de seu contexto de atuação.

\section{Considerações}

Com o objetivo de analisar a articulação entre teoria e prática, por meio de ambientes on-line na formação de professores, com base na literatura, foram apresentados estudos que analisam essa inter-relação na formação inicial (presencial, a distância ou híbrida) e evidenciam casos que concretizam a articulação entre teoria, prática e outros aspectos em que prevalece a dicotomia entre ambas, mesmo em situações de formação a distância, quando o cursista pode ser um 
professor em exercício, como tem ocorrido com frequência no Brasil devido às exigências de nível superior para o exercício da docência.

Ao assumir como pressuposto que a articulação entre teoria e prática, consubstanciada na práxis, é uma categoria fundante na formação inicial e continuada, este texto tratou da formação continuada de professores por meio de ambientes on-line e analisou como essa inter-relação se concretiza em um contexto específico.

A análise das intervenções nesse contexto específico de formação continuada no ambiente on-line evidencia a articulação entre teoria e prática como eixo norteador da formação, o qual se estabelece na ação por meio do diálogo reflexivo e criativo entre alunos-professores e professores-formadores, segundo a espiral da aprendizagem (VALENTE, 2005).

Neste estudo, os depoimentos reproduzidos indicam que os alunos-professores tornaram-se mais reflexivos, ao demonstrarem postura autônoma e crítica sobre o contexto de escolha, utilização e avaliação dos materiais didáticos digitais em suas práticas pedagógicas, além de terem reconstruído essas práticas subsidiados pela teoria. As intervenções enfatizaram, a princípio, a reflexão sobre a experiência do professor e, em seguida, a teoria, para compreender, recriar e desenvolver a prática, com novas reflexões, em outros patamares de compreensão. Portanto, foi possível refletir sobre a prática e praticar a teoria, com a ressignificação de ambas (ALMEIDA, 2000).

No entanto, a formação continuada on-line analisada não se encerra com a conclusão deste artigo. Mas corrobora a congruência entre o processo de transformação dos alunos-professores e dos professores-formadores, que, juntos, mergulham em um processo reflexivo de formação contextualizada em que todos aprendem, o que traz contribuições efetivas aos novos cenários de formação e pesquisa.

\section{REFERÊNCIAS}

ABREU, R. S.; LANZARINI, J. N. Pibid/Unisc: educação presencial e a distância: integrando reflexão, teoria e prática na formação de professores. Trabalho apresentado no 19을 Congresso Internacional ABED de Educação a Distância. Salvador, BA, 2013. Disponível em: <www.abed.org.br/congresso2013/cd/111.doc’3. Acesso em: 18 mar. 2014.

ALMEIDA, M. E. B. O computador na escola: contextualizando a formação de professores. Praticar a teoria, refletir a prática. 265 f. Tese (Doutorado) - Programa de Pós- 
-Graduação em Educação: Currículo. Pontifícia Universidade Católica de São Paulo. São Paulo, 2000.

ALMEIDA, M. E. B. Inclusão digital do professor: formação e prática pedagógica. São Paulo: Articulação, 2004.

ALMEIDA, M. E. B. Educação, projetos, tecnologia e conhecimento. 2. ed. São Paulo: Proem, 2005.

ALMEIDA, M. E. B. Tecnologias na educação, formação de educadores e recursividade entre teoria e prática: trajetórias do programa de pós-graduação em educação e currículo. Revista e-Curriculum, São Paulo, v.1, n.1, dez./jul., 2005-2006.

ALMEIDA, M. E. B. Gestão de tecnologia, mídias e recursos na escola: o compartilhar de significados. Em Aberto, v. 22, n. 79, p. 75-89, 2009.

ALMEIDA, M. E. B. Formação de educadores a distância na pós-graduação: potencialidades para o desenvolvimento da investigação e produção de conhecimento. Educação \& Sociedade, São Paulo, v. 33, n. 121, p. 1053-1072, 2012.

ALMEIDA, M. E. B. (Coord.). Relatório técnico científico. O currículo da escola do século XXI - integração das TIC ao currículo: inovação, conhecimento científico e aprendizagem. Pontifícia Universidade Católica de São Paulo. São Paulo: CNPq, 2013.

ALMEIDA, M. E. B.; IANNONE, L. R.; SILVA, M. G. M. Educação a Distância: oferta, características e tendências dos cursos de licenciatura em pedagogia. Estudos e Pesquisas Educacionais, v. 3. São Paulo: Fundação Victor Civita, 2012. p. 279-354.

ALMEIDA, M. E. B.; PRADO, M. E. B. B. Design educacional contextualizado na formação continuada de educadores com suporte em ambientes virtuais. In: CONFERÊNCIA INTERNACIONAL DE TECNOLOGIAS DE INFORMAÇÃO E COMUNICAÇÃO NA EDUCAÇÃO, 5., 2007, Braga, Actas... Braga: Universidade de Minho, 2007.

ARAGÓN, R.; MENEZES, C. S.; NOVAK, S. Curso de graduação, licenciatura em pedagogia na modalidade a distância $(\mathrm{PEaD})$ : concepção, realização e reflexões. Cinted-UFRGS Novas Tecnologias na Educação, v. 11, n. 2, nov. 2013. Disponível em: <http:// seer.ufrgs.br/index.php/renote/article/download/43643/27461>. Acesso em: 22 fev. 2014.

BARRETO, R. G. As tecnologias na política nacional de formação de professores a distância: entre a expansão e a redução. Educação \& Sociedade, Campinas, v. 29, n. 104 - Especial, p. 919-937, out. 2008. Disponível em: <http://www.cedes.unicamp.br>. Acesso em: 22 fev. 2014.

BRASIL. Conselho Nacional de Educação. Resolução CNE/CP Nº 1, de 15 de maio de 2006. Institui Diretrizes Curriculares Nacionais para o Curso de Graduação em Pedagogia, licenciatura. Diário Oficial da União, Brasília, DF, 16 maio 2006, Seção 1, p. 11.

BRASIL. Presidência da República. Lei n. 9.394, de 20 de dezembro de 1996. Estabelece as diretrizes e bases da educação nacional. Diário Oficial da União, Brasília, DF, 23 dez. 1996. 
CAVALLO, D. O Design emergente em ambientes de aprendizagem: descobrindo e construindo a partir do conhecimento indígena. Revista Teoria e Prática da Educação, Universidade Estadual de Maringá, PR. v. 6, n. 14, Edição Especial, 2003.

DBRC - Design-Based Research Collective. Design-based research: an emerging paradigm for educational inquiry. Educational Researcher, v. 5, n. 8, 2003.

DUFFY, T. M.; CUNNINGHAM, D. Constructivism: implications for the design and delivery of instruction. In: JONASSEN, D. H. (Ed.). The handbook of research on educational communications and technology. New York: Macmillan, 1996. p. 170-198.

GARCÍA, C. M. Formação de professores. Para uma mudança educativa. Porto: Porto Editora, 1999.

GATTI, B. A. Educação, escola e formação de professores: políticas e impasses. Educar em Revista, n. 50, p. 51-67, out./dez. 2013. Curitiba: UFPR. Disponível em: < http://www. scielo.br/pdf/er/n50/n50a05.pdf>. Acesso em: 20 mar. 2014.

GATTI, B. A.; BARRETO, E. S. S. (Coords.). Professores do Brasil: impasses e desafios. Brasília: Unesco, 2009.

GATTI, B. A.; NUNES, M. M. R. (Orgs.). Formação de professores para o ensino fundamental: estudo de currículos das licenciaturas em pedagogia, língua portuguesa, matemática e ciências biológicas. São Paulo: FCC/DPE, 2009. Disponível em: $<$ http:// www.fcc.org.br/pesquisa/publicacoes/textofcc/arquivos/1463/arquivoAnexado.pdf $>$. Acesso em: 1 jul. 2013.

GIMENO SACRISTÁN, J.; PÉREZ GÓMEZ, A. Compreender e transformar o ensino. Porto Alegre: Artes Médicas, 1998.

GIOLO, J. A educação a distância e a formação de professores. Educação \& Sociedade. v. 29, n. 105, p. 1211-1234. 2008 [on-line]. ISSN 0101-7330. Disponível em: <http:// www.scielo.br/pdf/es/v29n105/v29n105a13>. Acesso em: 19 mar. 2013.

GODOI, K. Validação participativa de instrumentos avaliativos de software educativo por professores do ensino fundamental e médio. 219 f. Dissertação (Mestrado) - Programa de Pós-Graduação em Design, Universidade Federal do Paraná, Curitiba, 2009.

GODOI, K. Avaliação de material didático digital na formação continuada de professores do ensino fundamental: uma pesquisa baseada em design. 245 f. Tese (Doutorado) - Programa de Pós-Graduação em Educação: Currículo, Pontifícia Universidade Católica de São Paulo, São Paulo, 2013.

IMBERNÓN, F. La formación y el desarrollo profesional del profesorado. Hacia una nueva cultura profesional. España: Editorial Graó, de Serveis Pedagógics, 1998.

IMBERNÓN, F. Formação permanente do professorado: novas tendências. São Paulo: Cortez, 2009. 
IMBERNÓN, F. Formação docente e profissional: formar-se para a mudança e a incerteza. São Paulo: Cortez, 2010.

INEP. Censo da educação superior: 2011 - Resumo Técnico. Brasília: Instituto Nacional de Estudos e Pesquisas Educacionais Anísio Teixeira, 2013.

JONASSEN, D. O uso das novas tecnologias na educação a distância e a aprendizagem construtivista. Em Aberto, Brasília, DF, v. 16, n. 70, p. 70-88, abr./jun. 1996. Disponível em: <http://www.rbep.inep.gov.br/index.php/emaberto/article/view/1054/956>. Acesso em: mar. 2014.

NÓVOA, A. Os professores e a sua formação. Lisboa: Publicações D. Quixote, 1995.

PACHECO, J. A. O pensamento e a acção do professor. Porto: Porto Editora, 1995.

PÉREZ GÓMEZ, A. O pensamento prático do professor: a formação do professor como profissional reflexivo. In: NÓVOA, A. Os professores e a sua formação. Lisboa: Publicações D. Quixote, 1995.

PIRES, C. M. C.; MANRIQUE, A. L. A Proposta de curso de licenciatura em matemática nas modalidades presencial e a distância na PUC-SP. Trabalho apresentado no IX Encontro Nacional de Educação Matemática. Belo Horizonte, 2007. Disponível em: $<$ http:// www.sbembrasil.org.br/files/ix_enem/Html/posteres.html>. Acesso em: 13 mar. 2014.

PRADO, M. E. B. B. Educação a distância e formação do professor: redimensionando concepções de aprendizagem. 279 f. Tese (Doutorado) - Programa de Pós-Graduação em Educação: Currículo, Pontifícia Universidade Católica de São Paulo, São Paulo, 2003.

PRADO, M. E. B. B.; ALMEIDA, M. E. B. Formação de educadores: fundamentos reflexivos para o contexto da educação a distância. In: VALENTE, J. A.; BUSTAMANTE, S. V. (Orgs.). EAD e reflexão sobre a prática: a formação do profissional reflexivo. São Paulo: Avercamp, 2009.

PRADO, M. E. B. B.; ALMEIDA, M. E. B. Estratégias em educação a distância: a plasticidade na prática pedagógica do professor. In: VALENTE, J. A.; ALMEIDA, M. E. B. de (Orgs). Formação de educadores a distância e integração de mídias. São Paulo: Avercamp, 2007.

REDIG, J. Design é metodologia: procedimentos próprios do dia a dia do designer. In: COELHO, L. A. (Org.). Design método. Ed. PUC-Rio; Teresópolis: Novas Idéias, 2006.

REEVES, T. C. Socially responsible educational technology research. Educational Technology, v. 40, n. 6, p. 19-28, nov./dez. 2000.

SANCHEZ VAZQUEZ, A. Filosofia da práxis. 1. ed. Buenos Aires: Consejo Latinoamericano de Ciencias Sociales - CLACSO; São Paulo: Expressão Popular, 2007.

SAVIANI. D. Formação de professores no Brasil: dilemas e perspectivas. Poíesis Pedagógica, v. 9, n. 1, p. 7-19, jan./jun. 2011. Disponível em: <http://www.revistas. ufg. br/index.php/poiesis/article/view/15667>. Acesso em: 17 mar. 2014. 
SCHÖN, D. A. Formar professores como profissionais reflexivos. In: NÓVOA, A. Os professores e a sua formação. Lisboa: Publicações D. Quixote, 1995.

SCHÖN, D. A. Educando o profissional reflexivo: um novo design para o ensino e a aprendizagem. Porto Alegre: Artes Médicas Sul, 2000.

TARDIF, M.; LESSARD, C. O trabalho docente: elementos para uma teoria da docência como profissão de interações humanas. Petrópolis: Vozes, 2005.

VALENTE, J. A. Educação a distância: uma oportunidade para mudança no ensino. In: MAIA, C. (Coord.). Ead.br: educação a distância no Brasil na era da Internet. São Paulo: Anhembi Morumbi, 2000.

VALENTE, J. A. A espiral da espiral de aprendizagem: o processo de compreensão do papel das tecnologias de informação e comunicação na educação. $232 \mathrm{f}$. Tese (Livre-Docência) - Instituto de Artes, Universidade Estadual de Campinas, Campinas, São Paulo, 2005.

VALENTE, J. A.; PRADO, M. E. B. B.; ALMEIDA, M. E. B. (Orgs.). Educação a distância via internet. São Paulo: Avercamp, 2003.

VALENTE, J. A.; PRADO, M. E. B. B.; ALMEIDA, M. E. B. Educação a distância via internet. São Paulo: Avercamp, 2005.

VIEIRA PINTO, A. O conceito de tecnologia. Rio de Janeiro: Contraponto, 2005. v. 2.

Texto recebido em 22 de novembro de 2014.

Texto aprovado em 10 de dezembro de 2014. 